Journal of Animal and Veterinary Advances 10 (13): 1656-1659, 2011

ISSN: $1680-5593$

(C) Medwell Journals, 2011

\title{
Chewing Lice (Insecta: Phthiraptera) on Mallards (Anas platyrynchos) in Turkey
}

\author{
Nursel Aksin \\ Elazig Health High School, Firat University, 23119 Elazig, Turkey
}

\begin{abstract}
This research was conducted to determine species of chewing lice (Phithiraptera) on mallard (Anas platyrynchos). For this purpose, twelve mallards (Anseriformes: Anatidae), obtained in different areas of Elazig province (Eastern Anatolian region) of Turkey from 2004 and 2006, during the hunting season between October to February were examined in terms of chewing lice. Three different chewing lice species were found on the infested mallards. These species were identified as Anaticola crassicornis (Scopoli, 1763), Trinoton querquedulae (Linnaenus, 1758) and Anatoecus sp. (nymph). In this study, the evidence of A. crassicornis, T. querquedulae and Anatoecus sp., on mallards is reported for the 1st time in Turkey.
\end{abstract}

Key words: Chewing lice, mallards, Anaticola crassicornis, Trinoton querquedulae, Anatoecus sp., Turkey

\section{INTRODUCTION}

It has been reported in the recent taxonomic data that $>4000$ Mallophaga species are associated with birds. Hellenthal et al. (2003) classified the genara of Mallophaga and the Lice species as to their host and illustrated that some important morphological characters for identification of the species and all genara.

According to Hellenthal et al. (2003) reported that A. crassicornis and Trinoton querquedulae were found on duck. It was reported in studies carried out in various countries that ducks were infested with $A$. crassicornis, T. querquedulae and Anatoecus species (Castresana et al., 1999; Hinojosa-Saez et al., 2009). Castresana et al. (1999) reported in a study that A. crassicornis, T. querquedulae and Anatoecus species were common on duck species of Anas acuta, A. clypeata, A. crecca, A. platyrynchos, $A$. penelope and $A$. strepera all of which belong to the family of Anatidae.

Clay and Hopkins (1960) noted that Trinoton species were classified in 4 groups as Femoratum, Aculeatum, Gambense and Querquedulae group described the significant morphological characteristics of each. The researchers (Clay and Hopkins, 1960) also produced an identification key by stating that Querquedulae group was divided into two as T. querquedulae found in the hosts belonging to Anas species and T. anserium found in the hosts belonging to Anser species. The researchers as Clay and Hopkins (1960) reported that T. querquedulae was found on Anas crecca that they had long brush setae on the 3rd femur that there were aggregates of short brush setae on 4-5 sternites and finally that the dorsal wall of the female genital area was thicker. Seguy noted that the head and the male genital organ were important in the differential identification of $A$. crassicornis and that the tip of the penis which is in the shape of a straight tube ending proximally. Ansari (1947) reported that female $A$. crassicornis ranged between 2.82 and $3.90 \mathrm{~mm}$ while the male $A$. crassicornis measured $2.56 \mathrm{~mm}$ and that the length of female T. querquedulae measured $4.51 \mathrm{~mm}$. No studies could be found about the presence of Mallophaga species on mallards in Turkey.

The present study is the 1st to establish the presence of $A$. crassicornis and T. querquedulae species on mallards (Anas platyrhynchos) in Turkey. Important morphological characteristics and measurements of these species have been laid down.

\section{MATERIALS AND METHODS}

Collection of mallards: The present survey was conducted to determine species of chewing lice on mallards. For this purpose, twelve mallards captured from different areas of Elazig province (Eastern Anatolian region) of Turkey in 2004 and 2006 during the hunting season between October and February were killed. Each mallard was brought to the laboratory in a transparent bag and their protocols were noted.

Laboratory method and identification: Transparent bag was placed immediately on freezing until, it could be examined for ectoparasites. Each frozen mallards was kept for approximately $30 \mathrm{~min}$ at room temperature before inspection. Thereafter each mallards was placed in a white tray and thoroughly brushed for collection of 


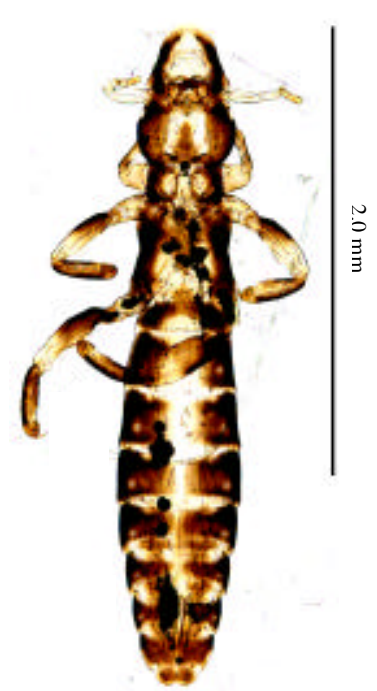

Fig. 1: Anaticola crassicornis (male)

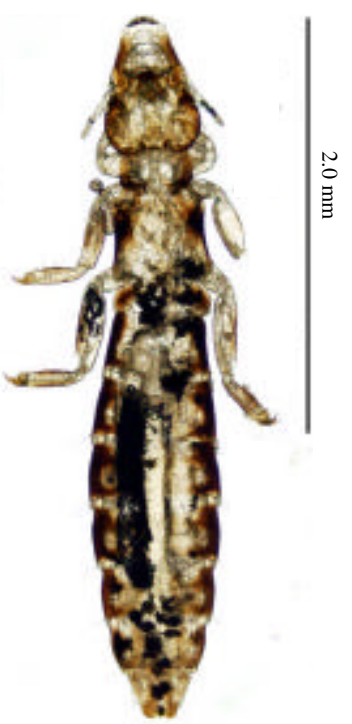

Fig. 2: Anaticola crassicornis (female)

ectoparasites. The ectoparasites were collected under a stereo-microscope by needle. The lice collected were transferred into petri dishes containing $70 \%$ alcohol and each dish was assigned a number.

The lice were kept in lactophenol for 7 days for the transparenting procedure. Transparented lice were mounted on slides in Foure forte medium and examined under a microscope. Transparented lice were examined under a microscope. A. crassicornis (Fig. 1-2), T. querquedulae (Fig. 3) and Anatoecus sp. were identified according to literature data (Ansari, 1947, 1951; Castresana et al., 1999; Clay and Hopkins, 1950, 1951, 1960; Clay, 1969; Hinojosa-Saez et al., 2009).

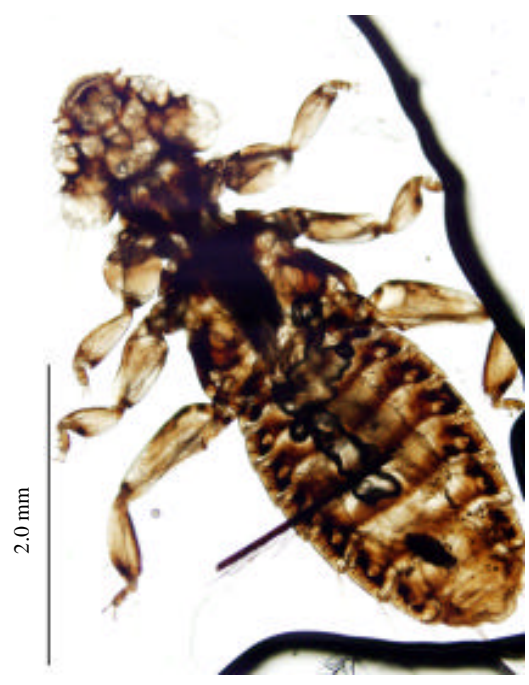

Fig. 3: Trinoton querquedulae (female)

The morphological description of $A$. crassicornis and T. querquedulae species was based on microscopy and measurements were made.

\section{RESULTS AND DISCUSSION}

Out of the twelve mallards examined throughout the study, ectoparasites were found on 6(50\%) and mallards were infested with at least one chewing Lice species. The prevalance of chewing Lice species on infested mallards is as follows: $4(66 \%)$ A.crassicornis, $1(17 \%)$ T. querquedulae and 1 (17\%) Anatoecus sp.

Anaticola crassicornis (Scopoli, 1763): The microscopic examination of $A$. crassicornis showed that the females were larger than males (Fig. 1-2) head longer than broader. Clypeus narrowly rounded anteriorly, dorsal anterior plate differing slightly in the two sexes that of the female generally semi-lunate, longer than wide, rounded anteriorly and concave posteriorly with a ventral groove containing two setaes arising from unsclerotized spaces. Dorsal surface of head with two pustulated setae immediately above the level of the large antennal fossae. Antennae 5-segmented, normal in female in the male 1 segment robust. Temples swollen; marginal bands broad; eyes prominent with distinct ocular blotch. Prothorax small with a narrow median groove, pterothorax larger and slightly wider than prothorax, sternal plates of pterothorax is large. Legs comparatively long. Abdomen narrowed and elongated, 1 segment narrow. Male genitalia well formed, basal plate long and slender; penis straight, long, cylindrical, curved toward each other. Measurements of this species are shown in Table 1. 
Table 1: Measurements (mm) of $A$ crassicornis and T. querque dulce

\begin{tabular}{lcc}
\hline Chewing lice species collected & Female & Male \\
\hline A. crassicornis & & \\
Head length & 0.65 & 0.62 \\
Head width & 0.46 & 0.41 \\
Thorax & 0.65 & 0.66 \\
Abdomen length & 2.10 & 1.64 \\
Abdomen width & 0.57 & 0.51 \\
Total length & 3.40 & 2.92 \\
T. querquedulae & & \\
Head length & 0.78 & - \\
Head width & 1.31 & - \\
Thorax & 1.55 & - \\
Abdomen & 2.40 & - \\
Abdomen width & 1.44 & - \\
Total length & 4.73 & - \\
\hline
\end{tabular}

Trinoton querquedulae (Linnaenus, 1758): Adult female $4.73 \mathrm{~mm}$ length (Fig. 3). Head triangular in shape than long, greates width at temporal region rounded and broader. Gular region with short stout spine-like setae. Antennae small, concealed in grove on under side of the head palpi well developed. Thorax strongly developed and heavily chitinized, protohrax large and with sharply angular lateral wings. Mesothorax and metathorax distinctly separated, mesothorax narrower and shorter than the metathorax. Legs stout, short and heavy, tarsi quite short and stout, legs have two tarsal claws, posterior 3rd femora with a sharply defined brushes setae on the ventral side; Abdomen elongated, sternites 4-5 scattered bruches of small setae Measurements of this species are given in Table 1.

Species A. crassicornis, T. querquedulae, Anatoecus icterodes and $A$. dentatus are common on Anatidae birds (Hellenthal et al., 2003). Castresana et al. (1999) identification that chewing Lice species were found on different ducks and reported that A. crassicornis, $T$. querquedulae and $A$. icterodes were found on Anas platyrynchos in the Iberian Peninsula. Martin-Mateo (2006) recorded that they found $A$. crassicornis and T. querquedulae on Anas platyrynchos in the Spain. Hinojosa-Saez et al. (2009) recorded that they found $55.4 \% \quad A$. crassicornis, $36.9 \%$ T. querquedulae and $26.1 \%$ A. icterodes on Anas georgica in Chile.

Rekasi et al. (1997) found that of the Anas platyrynchos were infested with $54.2 \% \mathrm{~A}$. crassicornis and $12.5 \% \mathrm{~T}$. querquedulae. In the present study, out of the 12 wild ducks examined, 6 (50\%) were infested with $4(66 \%) \quad A$. crassicornis, $1(17 \%)$ T. querquedulae and 1 (17\%) Anatoecus sp.

Seguy and Eichler and Vasjukova recorded in the differential identification of $A$. crassicornis that their antenna consisted of five segments, these formations seemed normal in females while one segment looked stronger in males and that the genital organ in males was well-formed with a thin, straight and cylindrical penis which was slightly in curved laterally. Ansari (1947) noted that the head and the male genital organ were important in the differential identification of $A$. crassicornis and that the tip of the penis which is in the shape of a straight tube ending proximally was noteworthy. In this study, antenna consisted of five segments, normal in female with one segment looking stronger in males and whose genital organ was well-shaped. Male genitalia and other morphologic characteristics were similar to those reported by Ansari (1947).

Castresana et al. (1999) stated that A. crassicornis was found particularly on Anseriformes that one setae on the frontal head in front of the frontal clypeus was thicker and that the females measured $3.39 \mathrm{~mm}$ and males $2.78 \mathrm{~mm}$ in length. Clay and Hopkins (1951) recorded that the head length was $0.68 \mathrm{~mm}$, head width was $0.46 \mathrm{~mm}$, abdomen length was $2.10 \mathrm{~mm}$, abdomen width was $0.53 \mathrm{~mm}$ and the total length was $3.40 \mathrm{~mm}$ in the female $A$. crassicornis while in males, the head length was $0.67 \mathrm{~mm}$, head width was $0.43 \mathrm{~mm}$, abdomen length was $1.63 \mathrm{~mm}$, abdomen width was $0.50 \mathrm{~mm}$, total length was $2.92 \mathrm{~mm}$. It was observed in the present study that the largest female of A. crassicornis were $3.4 \mathrm{~mm}$ and head length $0.65 \mathrm{~mm}$, head width $0.46 \mathrm{~mm}$, thorax length $0.65 \mathrm{~mm}$, abdomen length $2.10 \mathrm{~mm}$, abdomen width $0.55 \mathrm{~mm}$.

The largest male of $A$. crassicornis were $2.92 \mathrm{~mm}$ and head length $0.62 \mathrm{~mm}$, head width $0.41 \mathrm{~mm}$, thorax length $0.66 \mathrm{~mm}$, Abdomen length $1.64 \mathrm{~mm}$, Abdomen width $0.51 \mathrm{~mm}$. In this study, female and male of $A$. crassicornis measurements were similar to those reported by the Clay and Hopkins (1960) that T. querquedulae was found on Anas crecca that they had bruch setae on the 3rd femur that there were aggregates of bruch setae on 4-5 sternites and finally that the dorsal wall of the female genital area was thicker. Eichler and Vasjukova used pictures to demonstrate that the structure of the hair found in the gular region was important in the differential identification of Trinoton and that the hair had a different arrangement and structure in each Trinoton species.

Castresana et al. (1999) reported that the total length of the female $T$. querquedulae ranged between 5.37 and $5.83 \mathrm{~mm}$ and that these species were found only on duck species of Anas as their host, also reported that they had setae on the gular plate and the ventral surface of the thorax with brush setae aggregates on the 3rd femur and 4-5 sternites. In this study, gular region were short stout spine-like setae. Meso and metathorax were markedly separated, there were long bruch setae on the ventral part of the 3rd femur and there was a small aggregate of bruch setae on 4-5 sternites. Both the properties of the concerned structures and other morphological characteristics are consistent with the results of the afore mentioned researchers. Ansari (1951) measured 
the total length of the female $T$. querquedulae as $4.51 \mathrm{~mm}$, length of the head as $0.74 \mathrm{~mm}$, length of the thorax as $1.48 \mathrm{~mm}$ and length of the abdomen as $2.28 \mathrm{~mm}$. Clay and Hopkins (1950) specified the total length of females as $6.10 \mathrm{~mm}$, length of the head as $0.90 \mathrm{~mm}$, width of the head as $1.33 \mathrm{~mm}$, length of the abdomen as $3.26 \mathrm{~mm}$ and width of the abdomen as $1.69 \mathrm{~mm}$. It was observed in the present study that the female $T$. querquedulae were $4.73 \mathrm{~mm}$ in length and head length $0.78 \mathrm{~mm}$, head width $1.31 \mathrm{~mm}$ thorax length $1.55 \mathrm{~mm}$, abdomen length $2.40 \mathrm{~mm}$, abdomen width $1.44 \mathrm{~mm}$. In this study, female T. querquedulae measurements were similar to those reported by the researchers (Clay and Hopkins, 1950 ).

\section{CONCLUSION}

In this study, the evidence of $A$. crassicornis, T. querquedulae and Anatoecus sp. on Mallards (Anas platyrynchos) is reported for the 1st time in Turkey.

\section{ACKNOWLEDGEMENT}

I express thanks to Prof. Dr. Bilal Dik (Department of Parasitology, Faculty of Veterinary Medicine, Selcuk University, Konya, Turkey) for his kind help.

\section{REFERENCES}

Ansari, M.A.R, 1947. Mallophaga (Ischnocera) infesting birds in the Punjab (India). Proc. Natl. Inst. Sci. India, 13: 253-303.

Ansari, M.A.R, 1951. Mallophaga (Amblycera) infesting birds in the Panjab (India). Proc. Natl. Inst. Sci. India, 17: 127-203.
Castresana, L., A. Notario and P.M. Mateo, 1999. Study of the ectoparasitic mallophaga of Anatidae (Insecta, Mallophaga) in the Iberian Peninsula. Identification, biometric characteristics and biological aspects. Zool. Baetica., 10: 63-86.

Clay, T. and G.H.E. Hopkins, 1950. The early literature on Mallophaga. Part I. 1758-1762. Bull. Br. Mus. Nat. Hist., Entomol., 1: 221-272.

Clay, T. and G.H.E. Hopkins, 1951. The early literature on Mallophaga. Part II, 1763-1775. Bull. Br. Mus. (Nat. Hist.) London Entomol., 2: 1-37.

Clay, T. and G.H.E. Hopkins, 1960. The early literature on Mallophaga (Part IV, 1787-1818). Bull. Br. Mus. (Nat. Hist.) Entomol., 9: 1-61.

Clay, T., 1969. A key to the genera of the menoponidae (Amblycera: Mallophga: Insecta). Bull. Br. Mus. Entomol., 24: 1-40.

Hellenthal, R.A., R.L. Palma, K.P. Johnson, D.H. Clayton and R.D. Price, 2003. Chewing Lice: World Checklist and Biological Overview. Illinois Natural History Survey, Illinois, ISBN-13: 978-1882932085, pp: 501.

Hinojosa-Saez, A., D. Gonzalez-Acuna and M. GeorgeNascimento, 2009. Host specificity, prevalence and between-sites variation in metazoan parasites of Anas georgica Gmelin, 1789 (Aves: Anseriformes) in Chile. Revista Chilena Historia Nat., 82: 337-345.

Martin-Mateo, M.P., 2006. Diversity and distribution of species of Mallophaga (Insecta) on birds and mammals from Comunidad de Madrid. Graellsia, 62: $21-32$.

Rekasi, J., L. Rozsa and B.J. Kiss, 1997. Patterns in the distribution of avian lice (Phthiraptera: Amblycera, Ischnocera). J. Avian. Biol., 28: 150-156. 